\title{
CONTRIBUTOS DAS MEMÓRIAS NARRADAS PARA A CONSTRUÇÃO \\ DA(S) IDENTIDADE(S) DAS CRIANÇAS DE MAISHA ${ }^{1}$
}

Luciete Bastos ${ }^{2}$

Sandra Pereira Tosta

\author{
O olho vê, \\ a lembrança revê, \\ e a imaginação transvê. \\ É preciso transver o mundo. \\ Manoel de Barros (2000)
}

\section{INTRODUÇÃO}

A epígrafe de Manoel de Barros nos faz pensar sobre a importância do olhar atento para enxergar, pois é por esse processo que registramos os acontecimentos que significam para nós. E o que significa é memorizado em imagens que ficam como que guardadas na memória para que, num presente qualquer, sejam acionadas, revisitadas, (re)lembradas. Nesse processo, imiscuímos a imaginação que nos ajuda a representar o vivido com nossos olhos internos, que nos fazem construir algo novo sobre este vivido que foi selecionado pela memória e (re)criado, para que possamos, como o autor descreve, transver o mundo, ver o mundo para além do que apenas olhamos.

A memória mantem estreita relação com a pesquisa que tem como objeto empírico as narrativas extra e intra escolares como instância mediadora na/para construção das identidades des crianças quilombolas de Maisha, Caetité-Bahia. Antes de adentrar à discussão acerca de alguns temas que fazem parte da construção da problemática da pesquisa, cabe situá-los em seus contextos.

\section{BREVE APRESENTAÇÃO DA COMUNIDADE DE MAISHA E SUA ESCOLA}

A comunidade está localizada a, aproximadamente, 70 quilômetros da sede do município de Caetité, na região da Bacia do Rio São Francisco, denominada Alto Sertão da Bahia, Brasil. O povoado é humilde, as casas só possuem reboco na fachada. A agricultura é de subsistência, cuidada pelas famílias. Na comunidade, vivem cerca de 300 pessoas, resultantes dos

${ }^{1}$ Maisha: nome africano que significa "vida", usado para designar a comunidade onde se realizará a pesquisa de campo.

\footnotetext{
${ }^{2}$ Doutoranda do Programa de Pósgraduação em Educação da PUCMinas. Professora da UNEB Caetité- BA

${ }^{3}$ Doutora em Antropologia Social. Professora da PUC-Minas.
} 
casamentos entre pessoas no mesmo grupo. Não há uma pessoa branca residente no local. A comunicação não é muito difícil, porque, embora na comunidade não haja linha telefônica, as pessoas vivem indo e vindo da sede do município, cidades e distritos circunvizinhos. A comunidade valorizam muito a escola, pois acreditam ser o único caminho para que seus filhos

conquistem ascensão social. Por isso, não há criança fora da escola.

Estas crianças frequentam a "Escola Municipal 25 de Dezembro" que atende alunos do Infantil ao $5^{\circ}$ ano. Funciona nos turnos matutino e vespertino, sendo quatro turmas no primeiro turno e uma no segundo. No turno matutino, as classes são organizadas com crianças em idade compreendida entre 03 e 05 anos (inclusive) na Educação Infantil; e de 06 a 09 anos no Ensino Fundamental $\left(1^{\circ}, 2^{\circ}, 3^{\circ}, 4^{\circ}\right.$ e $5^{\circ}$ anos). As turmas do Infantil I e II, do $1^{\circ}$ e $2^{\circ}$ anos e do $4^{\circ}$ e $5^{\circ}$ funcionam em classes multisseriadas ${ }^{4}$. No vespertino, além de uma turma do curso regular, funciona também uma turma organizada conforme a proposta do Programa Mais Educação ${ }^{5}$. Este programa sugere a escola, conforme projeto educativo que adota o desenvolvimento de atividades de “acompanhamento pedagógico; educação ambiental; esporte e lazer; direitos humanos em educação; cultura e artes; cultura digital; promoção da saúde; comunicação e uso de mídias; investigação no campo das ciências da natureza e educação econômica". (MEC, 2007)

Os alunos que concluem até o $5^{\circ}$ ano, na comunidade, prosseguem seus estudos no Distrito de Caldeiras, ou no Município de Igaporã, este mais próximo da comunidade do que o município de Caetité. Essas escolas urbanas nem sempre recebem de forma adequada esses alunos. Na pesquisa de campo, pretende-se investigar um grupo de alunos do $5^{\circ}$ ano da escola 25 de Dezembro, em Sambaíba e, posteriormente, o mesmo grupo na Escola de $1^{\circ}$ Grau Professora Emiliana Nogueira Pita, no Distrito de Caldeiras, para onde as crianças de Maisha migram. De igual modo, pretende-se investigar um outro grupo composto por alunos não oriundos da comunidade quilombola. $\mathrm{O}$ objetivo, ao fim e ao cabo, é compreender, pelas narrativas das crianças quilombolas, o que as crianças pensam sobre si e o que as outras crianças pensam sobre elas, que constituem indícios possíveis para a construção da identidade desses alunos.

${ }^{4}$ São classes heterogêneas que congregam estudantes de séries e níveis cognitivos diferentes e são atendidos, simultaneamente, pelo mesmo professor; situação exclusiva da zona rural do município, onde o número de professor insuficiente para a demanda.

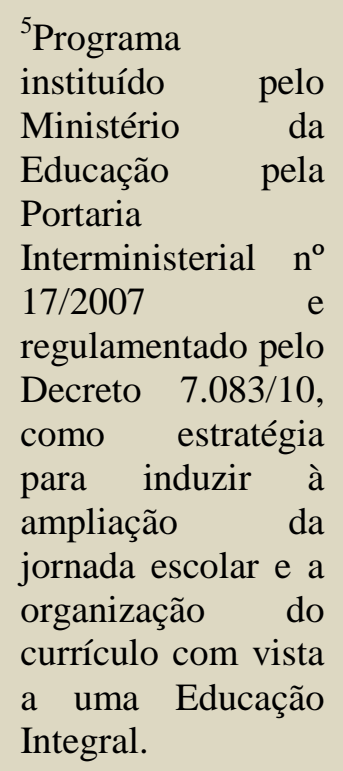

${ }^{5}$ Programa

instituído elo

Ministério da Educação la Interministerial $\mathrm{n}^{\circ}$ $17 / 2007$ e Decreto 7.083/10 como estratégia para induzir à ampliação da jornada escolar e a organização do currículo com vista Integral. 


\section{A IMPORTÂNCIA DA COMUNIDADE PARA A EDUCAÇÃ̃o QUILOMBOLA}

A educação quilombola é compreendida como um processo amplo, que inclui a família, a convivência com os outros, as relações de trabalho, as crenças e as vivências na escola, nos movimentos sociais e em outras organizações da comunidade. A criança, embora uma pessoa em formação na sua integralidade, também participa dessas relações cotidianas e delas extrai ensinamentos que leva para vida. Considerando a educação como um dos direitos humanos básicos para a formação da pessoa, a luta por este direiro tem sido uma das pautas dessas comunidades, não apenas pela conquista ao acesso à escola, mas, principalmente, às condições de permanência com qualidade e um ensino que contemple as identidades, as culturas e os valores dos remanescentes. Daí a importância de uma escola com foco na valorização das identidades como forma de fortalecimento das culturas e das causas quilombola.

Por essa perspectiva, a relação sujeito/terra faz parte da própria identidade constitutiva da pessoa quilombola, fato que impõe a necessidade de uma educação que considere a experiência de vida das pessoas nas relações sociais, como construção do saber e as especificidades de cada comunidade nas relações de pertencimento. A partir desta compreensão é que trazemos as narrativas intra e extra escolares como mecanismos simbólicos de fortalecimento das identidades dessas crianças, levando em conta dois olhares relevantes para tal argumento: Primeiro, a existência de uma dimensão da identidade que é comum a todos os remanescentes que diz da sua relação com o território e da condição de cidadãos de direito, com histórias de vida que trazem indícios que os identificam como pertencentes a um grupo. Segundo, as comunidades quilombolas não são portadoras de culturas idênticas e autóctones, cada grupo de remanescentes traz suas especificidades conforme a tradição do grupos dos quais foi formado. Por isso mesmo, é preciso ponderar as diferentes influências culturais, sejam aquleas oriundas da formação dos grupos, sejam aquelas com as quais são dinamicamente transformados. Pensamos, portanto, que o compromisso e envolvimento da escola com a comunidade, numa parceria e permuta de conhecimentos, pode garantir 
melhores resultados não só na aprendizagem de conteúdos institucionalizados, mas, também, na construção e fortalecimento da identidade dessas crianças. Nesse contexto, torna-se imperativo repensar a educação em diferentes perspectivas e situar o seu papel como mediadora das diversas e diferentes formas de relação entre os sujeitos e o mundo.

A fim de alcançar os objetivos propostos na pesquisa, analisaremos narrativas orais em torno da memória e da cultura como aporte teórico metodológico da investigação. Estudar as narrativas orais, constituídas como corpus documental por excelência, para análise de sua contribuição para a construção da identidade das crianças da comunidade de Maisha perpassa, necessariamente, pela lembrança e reconto de "fatos" vivenciados num dado momento da vida do participante da pesquisa. E também de histórias ouvidas que se tornaram referência para a comunidade e que, por essa razão, vem sendo transmitidas de geração em geração, configurando o que poderíamos chamar de tradição. Tradição no sentido vivo de histórias e memórias que são recorrentemente evocadas e que, por isto mesmo, são marcas de uma comunidade.

Deste modo, entendendo que o presente estudo tem interrogado a memória com novos problemas e diferentes abordagens, há que se considerar uma força que impele para a reformulação das questões propostas, inicialmente, para a pesquisa, modificando e adequando a metodologia às necessidades explicativas prementes. Por essa razão, para este texto, organizamos algumas temáticas preliminares, seguindo três categorias, separadas apenas por questões didáticas, que serão consideradas no estudo: 1 . História e Memória; 2. As narrativas de memórias; 3. A identidade e o multiculturalismo.

\section{HISTÓRIA E MEMÓRIA}

A História configura-se como sendo um campo de produção de conhecimentos, alimenta-se de teorias explicativas e de fontes que se constituem indícios, vestígios e pistas que nos ajudam a compreender as ações humanas no tempo e no espaço. A modernidade fez estremecer as certezas e levou a questionar paradigmas. Desde a segunda metade do séc. XX tal 
reflexão fora enfrentada de diversas formas, sob diversos ângulos, inicialmente analisando-se as transformações pelas quais passou a disciplina ao longo dos séculos XIX e XX. A crise epistemológica por que passou a disciplina tornou relativa várias certezas dos historiadores. Passamos a questionar a noção de um tempo fixo, para defender a existência de temporalidades múltiplas; a objetividade vem sendo relativizada, pois assim como o historiador é fruto de seu tempo, também o é o discurso histórico por ele produzido. As fontes escritas também não são menos inverídicas do que as fontes orais, ambas devendo ser analisadas criticamente. O olhar, desconfiado e crítico, para as certezas absolutas, passou a ser a tônica do final do século vinte e critério indispensável àqueles que concebem a prática historiográfica como científica. Como diagnóstico dessa reflexão, falou-se, nesse momento, "de uma crise da história", iniciada na década de 1960 e dilatada entre as décadas de 1980 e 1990. (CHARTIER, 2009)

Nos anos de 1970, o interesse pela memória como documento histórico tem origem na historiografia de inspiração francesa. Embora a memória já se encontrasse implícita, principalmente nos estudos voltados para aspectos da cultura popular como: a vida em família, os hábitos e costumes de uma localidade, a religiosidade, dentre outros, que remetem à sua constituição social, apenas recentemente o interesse pela relação entre História e Memória induziu estudiosos a refletir acerca do conceito de memória. Se por um lado se (re)valorizam e se difundem esses estudos; por outro, tornaram-se alvo de diferentes discursos e de uma teoria vista como fragilizada. Nesse esforço de (re)pensar o conceito de memória, tornou-se fundamental revisitar as ideias de Maurice Halbwachs (1925) que elaborou uma espécie de "sociologia da memória coletiva". Em constante diálogo com a obra desse teórico, encontramos os trabalhos de historiadores como Pierre Nora (1993) e Michael Pollak (1989 e 1992).

Os estudos de Halbwachs (2004) contrapõem-se às ideias de Bergson (2004), para quem a memória ou é a imagem-lembrança (definida, individualizada), ou a memória-hábito (práticas do dia-a-dia), enfatizando a espontaneidade e a liberdade da memória (o passado se conserva inteiro e independente no espírito). Para Halbwachs (2004) lembrar não é reviver, é 
refazer, reconstruir, repensar com imagens e ideias de hoje as experiências do passado. E esta reconstrução dependerá de como o narrador se insere-se em um meio social onde se percebe como parte, ou seja, expressa uma identidade, por meio da qual se constituíra a memória coletiva. $\mathrm{Na}$ comunidade de remanescente os anciãos desempenham papel fundamental nessa reconstrução, pelas imagens do presente, da tradição por ele experimentada e que, agora partilha com os mais jovens e crianças.

Inspirado nas tese de Durkheim - que enfatiza o papel que as representações e ideias dos homens exercem na sociedade-, Halbwachs (2004) desloca o eixo de interesse do indivíduo para a sociedade. Destarte, boa parte do que somos, ou do que cremos ser, muitas de nossas lembranças ou mesmo de nossos ideais serem inspiradas em conversas e vivências coletivas. Com o passar do tempo, criamos uma história dentro de nós, que nos acompanha pela vida a fora e que é enriquecida por experiências de outras pessoas. Desse modo, cada memória individual é um ponto de vista sobre a memória construída coletivamente, pois, a cada instante, refazemos nossas lembranças e a todo tempo inserimos novos elementos, nos deslocando espacialmente e conhecendo novas pessoas. A memória do sujeito, construída a partir das referências e lembranças do grupo, refere- se a "um ponto de vista sobre a memória coletiva" (HALBWACHS, 2004, p.55). Em concordância a este autor, esse olhar deve ser analisado, considerando-se o lugar ocupado pelo sujeito no interior da comunidade, suas relações com outros sujeitos e a interação com outros grupos. A unidade coletiva é concebida como um espaço de conflitos e influências de uns sobre os outros, construindo lembranças que pertencem ao grupo e que formam um sistema que subiste enquanto sobreviver à memória grupal.

A origem de várias ideias, reflexões, sentimentos e paixões a nós atribuídas são, na verdade, instigadas pelo grupo no qual vivemos e interagimos. Para Halbwachs (2004, p.41): "Haveria, então, na base de toda lembrança, o chamado a um estado de consciência puramente individual quepara distingui-lo das percepções onde entram elementos do pensamento social - admitiremos que se chame intuição sensível”. Segundo este teórico, as lembranças podem, a partir da vivência em grupo, ser reconstruídas ou simuladas. Assim sendo, podemos criar representações do passado assentadas 
na percepção de outras pessoas, no que imaginamos ter acontecido ou pela internalização de representações de uma memória histórica. A lembrança de membros da comunidade, interligadas umas a outras, gera uma representação, não do que foi vivido, mas do que a comunidade acredita ter vivido, uma construção coletiva que se torna a memória histórica daquele povo. A lembrança, na definição de Halbwachs (2004, p. 76-84), "é uma imagem engajada em outras imagens". Ele argumenta, ademais, que "a lembrança é, em larga medida, uma reconstrução do passado com a ajuda de dados emprestados do presente, e além disso, preparada por outras reconstruções feitas em épocas anteriores e de onde a imagem de outrora manifestou-se já bem alterada" (Halbwachs, 2004, p.75-76).

Ecléa Bosi (1997), iminente pesquisadora da memória, desta feita, no Brasil, escreveu que a memória não é sonho, é trabalho: uma operação realizada no presente que suscita indagações sobre o pretérito. Dessa forma, seria ingênuo pensar que o passado sobrevive, tal como foi, e que se daria no inconsciente de cada sujeito. A lembrança é, pois, uma imagem construída com os materiais do presente, no conjunto de representações que povoam nossa consciência atual. Por mais nítida que nos pareça, não é a mesma imagem que experimentamos, porque nós não somos os mesmos de então, nossa percepção alterou-se e, com ela, nossas ideias, nossos juízos de realidade e de valor.

Assim, o simples fato de lembrar o passado, no presente, exclui a identidade entre as imagens de um e de outro, e propõe a sua diferença em termos de ponto de vista. Halbwachs (2004) e Bosi (1997), comungam da ideia de que as lembranças para os velhos não são pontos de fuga no cotidiano, como são para os adultos, pois aqueles podem se entregar mais detidamente à rememoração que lhes permitem ir ao encontro das lembranças. Geralmente, não se contentam em aguardá-las, tampouco de guardá-las para si, procuram precisá-las, interrogam outros velhos, percorrem seus guardados, fotos e cartas antigas, mas, sobretudo, sentem prazer em partilhar suas memórias, principalmente com os mais jovens. Frente a estas argumentações é que defendemos o interesse pelos anciãos da comunidade de Maisha, que são fontes valiosas de informações e de experiências, que podem possibilitar compreender a construção identitária de crianças por meio das narrativas. Esse 
recordar dos mais velhos numa comunidade, tem importante função social, porque são como guardiões das tradições: as receberam mais cedo que os outros e, também, porque dispõem de tempo bastante para transmitir suas lembranças, evocar tempos imemoriais e, geralmente, o fazem com prazer.

Nesse processo de rememoração, as lembranças podem ser simuladas ao entrar em contato com as lembranças de outras pessoas; mas não há, por outro lado, memória que seja "imaginação pura e simples", ou representação histórica que tenhamos construído que nos seja exterior. Tal processo de construção e reconstrução da memória passa por um referencial que é o sujeito.

Desse modo, para além de datas e nomes, acrescentamos à memória histórica percepções pessoais e subjetivas como "os quadros coletivos da memória (...) representam correntes de pensamento e de experiência onde reencontramos nosso passado, porque este foi atravessado por isso tudo [datas, nomes, etc.]" (HALBWACHS, 2004, p.71). Porquanto, memória coletiva é pautada na continuidade e deve ser vista sempre no plural, justamente, porque a memória de um indivíduo, ou de um país, está na base da formulação de uma identidade. A História, por outro lado, encontra-se pautada na síntese dos grandes acontecimentos da história de uma nação, o que faz das memórias coletivas apenas detalhes. Sobre esta relação, o autor escreve:

O que justifica ao historiador estas pesquisas de detalhe, é que o detalhe somado ao detalhe resultará num conjunto, esse conjunto se somará a outros conjuntos, e que no quadro total que resultará de todas essas sucessivas somas, nada está subordinado a nada, qualquer fato é tão interessante quanto o outro, e merece ser enfatizado e transcrito na mesma medida. Ora, um tal gênero de apreciação resulta de que não se considera o ponto de vista de nenhum dos grupos reais e vivos que existem, ou mesmo que existiram, para que, ao contrário, todos os acontecimentos, todos os lugares e todos os período estão longe de apresentar a mesma importância, uma vez que não foram por eles afetadas da mesma maneira" (HALBWACHS, 2004,p. 89-90).

Destarte, cada acontecimento é singular, na medida em que as circunstâncias em que ocorreu não se repetem de forma idêntica. Tampouco apresentam valor similar, pois para cada povo, em cada época distinta, o acontecimento é mais ou menos importante para seus sujeitos. A história de uma nação pode ser entendida como a síntese dos fatos mais relevantes a um 
conjunto de cidadãos, mas se encontra muito distante das percepções do indivíduo. Por isto, a diferenciação entre Memória e História estabelecida por Maurice Halbwachs(2004). A memória, segundo ele apoia-se no "passado vivido" que permite a constituição de uma narrativa sobre o passado do sujeito de forma viva e natural, mais do que sobre o "passado apreendido pela história escrita" (2004, p.75).

Desde a concepção de Pierre Nora (1993), a “memória é o vivido e a história é o elaborado. Então a memória permite atualizar a história a todo instante" (p.9). Argumentando sobre a relação entre História e Memória, assim como Halbwachs, este historiador também as opõe, na medida em que a memória tornou-se objeto da história, sendo por ela filtrada, o que impede o estabelecimento de diferenças entre a memória coletiva e a memória histórica. Nora (1993) afirma que a memória já não existe e tudo aquilo que se considera memória, atualmente, é história. Em vez de memória, o autor fala de "lugares de memória". Acabando por retomar parte do pensamento de Halbwachs (2004) acerca das relações entre história e memória: “a história começa somente do ponto onde acaba a tradição, momento em que se apaga ou se decompõe a memória social. Enquanto uma lembrança subsiste, é inútil fixá-la por escrito" (HALBWACHS, 2004, p.85). A diferença entre ambos é que para Halbwachs as lembranças são incorporadas pela história, na medida em que vão deixando de existir, ou na medida em que os grupos que as sustentavam deixassem de existir. Nora (1993), por sua parte, entende de forma mais ampla que a categoria memória deixou de existir, porque passou a ser reivindicada pelo discurso histórico. Por isso mesmo, as reflexões teóricas oferecidas por ambos é de grande valia quando se deseja observar para interpretar, as culturas de populações remanescentes de quilombos. 
Neste debate, vale ressaltar o pensamento do pesquisador Michael Pollak (1989) que não vê com tanto pessimismo as relações entre história e memória ou entre a memória oficial (nacional) e aquilo que denominou “memórias subterrâneas" em referência às camadas populares. Para ele, estas memórias marginalizadas abriram novas possibilidades no terreno fértil da História Oral e trazem à superfície memórias "que prosseguem seu trabalho de subversão no silêncio e de maneira quase imperceptível", aflorando "em momentos de crise em sobressaltos bruscos e exacerbados" (POLLAK, 1989, p. 3-15). Escreveu, também, que o processo de formação da dinâmica identitária, é construído por diferentes sujeitos, numa interação, permanente, entre o vivido e o aprendido, o vivido e o transmitido. A emergência dessas memórias ocasiona uma disputa ou uma luta entre a memória oficial e as memórias subterrâneas, num embate travado pela incorporação dessas memórias marginalizadas e/ou silenciadas, visando à afirmação, sobretudo, de uma identidade que, por pertencer a uma minoria, encontra-se à margem.

Assim posto, compreendemos que estudos sobre a memória retornaram ao meio acadêmico com muito vigor, numa conjuntura de globalização como a que vivemos, imposta pelo presente às sociedades e ao historiador que pretende investiga-las ${ }^{6}$. Fato que está incorporado, também, às lutas dos diversos movimentos sociais com o intuito de alargar o conceito de cidadania na sociedade e nas relações de poder, que permeiam toda atividade humana. Ambos os processos reclamam a identidade, seja ela de minorias, seja do ponto de vista nacional.

\section{NARRATIVAS E MEMÓRIAS}

O que temos aprendido, ao longo da pesquisa com as leituras do referencial teórico, é que o passado não é a presentific(ação) do fato como aconteceu, mas a percepção do narrador, via interpretação, daquilo que foi. $\mathrm{O}$ que exige por parte do pesquisador o cuidado necessário ao realizar um trabalho de investigação, usando como fontes as memórias dos sujeitos, que narram no tempo e no espaço presente o que "aconteceu", ou deveria ter acontecido. Considerando-se que se trata de uma possibilidade de "leitura" do

${ }^{6}$ Essa relação entre passado/presente é também discutida de forma minuciosa pelo historiador francês Jacques Le Goff no livro intitulado "Historia e Memória" (2003).

Para ele em sociedades

históricas a memória sempre teve um papel preponderante na definição de poderes. Como, por exemplo, na antiguidade, em que a memória era utilizada para três grandes interesses: 1 - construção dos mitos de origem; 2 o prestígio das famílias

dominantes, que se exprime pelas genealogias; $3-0$ saber técnico, que se transmite por geração a geração (TOSTA, PAIVA, 2011) 
que foi vivenciado, pois a narrativa daquele que viveu pode ajudar a reconstruir a história.

São importantes as contribuições de Henry Rousso (2002) ao explicar que a memória é a presença do passado e, ao mesmo tempo, é incontestavelmente da atualidade, pois é o momento atual que lança ao passado as indagações em busca de compreensão, possibilitando aos sujeitos que narram, uma reconstrução constante de si e do seu contexto. As memórias constituem-se, destarte, "[...] um elemento essencial das identidades, da percepção de si e dos outros" (ROUSSO, 2002, p. 95). Para este teórico, a memória coletiva de acontecimentos e representações do passado que se quer salvaguardar, se integra em tentativas mais ou menos conscientes de definir e de reforçar sentimentos de pertencimento e fronteiras sociais entre diferentes coletividades. Acrescenta, ainda, que a memória como reconstrução psíquica e intelectual traz ativamente uma representação seletiva do passado e esse passado não é apenas daquele que recorda, mas também do coletivo do qual o recordador fez/faz parte. Por essa razão, as memórias são componentes absolutamente necessários na (trans)formação das identidades dos sujeitos, das percepções de si e dos outros, daqueles com os quais conviveram ao longo de suas vivências em contextos sociais distintos. Outrossim, são experiências de vida, porque as memórias compartilhadas, por meio das narrativas, possibilitam ao narrador narrar-se, assim, é possível depreender que contamos uma história pessoal, mas que essa história é atravessada pelas histórias sobre nós que nos são narradas por outros.

Retornando ao pensamento de Maurice Halbwachs (2004), o ato de lembrar tem uma função de reforçar a coesão social, não pela coerção, mas pela "adesão afetiva", ao proporcionar ao indivíduo o sentimento de pertencimento a um determinado grupo que compartilha memórias, o que ele chamou de "comunidade afetiva". Essa coesão é obtida através dos "quadros sociais da memória", mecanismos através dos quais os valores são compartilhados pelos diversos grupos sociais. A memória do indivíduo encontra-se arraigada em contextos diversos que se aproximam pela subjetividade, mesmo que de modo incerto, simultâneo e incontrolável. É da combinação das redes de solidariedades múltiplas de informações em que 
estamos envolvidos socialmente que emerge a lembrança. É pelo recurso da linguagem que as narrativas vão ganhando sentido em relação ao grupo do qual o narrador fez ou faz parte, porque pressupõe um evento real vivido outrora em comum, que depende do contexto de referência no qual, atualmente, transitam o grupo e o sujeito que o atesta. A rememoração "dos acontecidos" possibilitará que as memórias individuais liguem-se à memória coletiva.

Com a pesquisa em cursos sobre as narrativas de quilombolas, sugerimos que, no momento em que a representação seletiva do passado dos remanescentes vai aparecendo em suas falas, é possível perceber sua inserção no contexto social do lugar Maisha. Desta forma, o ato de relembrar insere-se nas possibilidades múltiplas de elaboração das representações e de reafirmação de identidades múltiplas; e como afirma Marilena Chauí, no prefácio do livro de Ecléa Bosi (1997), o modo de lembrar é individual tanto quanto social. O grupo transmite, retém e reforça as lembranças, mas o recordador, ao trabalhálas, vai, paulatinamente, individualizando a memória comunitária e, nos modos de lembrar e nos fatos que lembra, estão impressos os significados. O que nos autoriza a dizer que a memória seleciona o que tem significado para aquele que lembra.

Walter Benjamin (1994), nos ensina que a oralidade é um dos elementos que dá à experiência individual e coletiva o seu peso tradicional na medida em que, através de um elemento dito, um testemunho histórico autêntico é entregue, passado de geração em geração. As lembranças de um grupo social podem ser entendidas como "documentos históricos" assim como os escritos, com igual valor, pois possibilitam outras versões sobre nossa história. No caso específico das populações negras, que foram descritas apenas como escravizadas ou libertas, a ausência dos matizes necessários para o entendimento do papel destas populações na formação do nosso país e de seu povo, encobre uma história. Em vista disto, uma revisão historiográfica na qual o negro seja visto como parte constituinte do povo brasileiro e que a escravidão não seja tratada como um passado distante, mas como fato que produziu marcas persistentes e que não receberam o devido tratamento em nossa formação social é de fundamental importância. Ainda mais que a escravidão do negropermanece na contemporaneidade mascarada sob outras 
formas de exploração e de expropriação de seus valores. Neste cenário, as questões que envolvem as populações quilombolas não devem ser tratadas como episódicas e isoladas, mas contextualmente e incluídas em planos de ações, alocação de recursos e realizações com prazos determinados.

Ainda segundo Benjamin (1994), as vivências experimentadas pelos atores sociais, individualmente, não devem ser desprezadas (Erlebniz). Há ainda uma operação que o sujeito realiza sobre si mesmo, que constitui o caráter primordial da experiência (Erfharung) e que não se trata de um "ensimesmamento", mas de um trabalho sobre si que o impele à atuação. No que diz respeito à narrativa, afirma que uma das características de muitos narradores natos é o senso prático: "O narrador retira da experiência o que ele conta: sua própria experiência ou a relatada pelos outros. E incorpora as coisas narradas à experiência dos seus ouvintes" (BENJAMIN, 1994, p. 201). É possível identificar dois aspectos distintos presentes no que se refere à experiência nas ideias desse filósofo. Um deles diz respeito à possibilidade de narrar, ou seja, de transmitir/comunicar a experiência; o outro aspecto diz respeito à impossibilidade da narrativa. Para Benjamim, a narrativa,

[...] tem sempre, em si, às vezes de forma latente, uma dimensão utilitária. Essa utilidade pode consistir seja num ensinamento moral, seja numa sugestão prática, seja num provérbio ou numa norma - de qualquer maneira, o narrador é um homem que sabe dar conselhos. (BENJAMIN, 1994, p. 200)

Se por um lado, a experiência está atrelada à transmissão, ao ato de contar, repartir, comunicar, falar sobre, ensinar e aconselhar através da narrativa, por outro, há um calar-se, uma mudez, um silenciar, dado que algumas experiências não podem ser expressas por palavras ou sons: são incomunicáveis, porque machucam, são dolorosas. Como é o caso de soldados que retornam emudecidos da guerra, empobrecidos de experiência comunicável, o vivido/sofrido testemunhado os emudecera pelo trauma, não conseguem transformar a experiência numa linguagem. Há, em toda experiência, sob a perspectiva benjaminiana, uma dimensão que é narrável e outra inenarrável, o que é conveniente ser dito e aquilo que é silenciado pela dificuldade de se verbalizar o vivido. O passado só se revela como imagem 
imprecisa e incerta, quando instigado por um motivador no presente. Com as palavras de Benjamin (1994, p. 202):

A verdadeira imagem do passado perpassa, veloz. O passado só se deixa fixar, como imagem que relampeja irreversivelmente, no momento em que é reconhecido. [...] Articular historicamente o passado não significa conhecê-lo 'como ele de fato foi'. Significa apropriar-se de uma reminiscência, tal como ela relampeja no momento do perigo.

Trabalhar com narrativas exige, outrossim, que compreendamos o contexto de sua produção como documento de análise para a pesquisa em educação. Analisar narrativas é descobrir que é na história vivida por seres humanos (velhos, adultos, jovens e crianças- por que não?) que as memórias narradas se apoiam. Desse modo, considerar as narrativas como objeto privilegiado de análise significa estar atento às sensibilidades, às percepções, às leituras de mundo, aos sentimentos daqueles que narram.

Haja vista que imiscuir-se pelos caminhos da memória é, muitas vezes, irromper em caminhos de dor, de fracassos, de prazer, de lutas, de encontros, desencontros, perdas, conquistas, frustrações e alegrias. Enfim, trabalhar com memórias, problematizando-as, analisando-as, é lidar com a vida em sua mais significativa pulsão. É descobrir que o narrador não revive o pretérito, trazendo intactas as memórias de um acontecimento, apenas materializa em discurso suas reminiscências, construindo (re)elaborações sobre o passado. $\mathrm{Ou}$ conforme já foi dito antes, o passado é construído a partir de preocupações e situações presentes.

Por tudo isto, apreendemos que narrativas são construídas socialmente, por isso o narrar gera um refazer-se. Mesmo que seja enfocado um mesmo evento, as narrativas não e repetem intactas, considerando que os lugares, as percepções e os sentimentos, bem como os sentidos atribuídos pelos sujeitos, vão se modificando com o tempo, ao longo das vivências coletivas, de inserções em grupos sociais diversos e de experiências múltiplas. Os narradores constroem suas reminiscências (trabalho, familiares, alegrias, dores, insucessos, vitórias, aspirações, medos e esperanças) no momento da narrativa, selecionando o que quer contar e ocultando o que não deseja revelar. 


\section{IDENTIDADE QUILOMBOLA}

Na Constituição Federal de 1988, foi assegurado às comunidades remanescentes de quilombos o direito às terras ocupadas, devendo o Estado atuar na titularização dessas terras. Do direito conquistado pelos movimentos negros, surge a identidade política do quilombola. Muitas comunidades, até então, ditas apenas "comunidades negras", ou que habitavam as chamadas "terras de preto", passam a se assumir quilombolas. Os quilombos são a materialização da resistência negra à escravização e uma das primeiras formas de defesa dos negros, contra não só esta condição, mas também à discriminação racial e ao preconceito. Diante deste fenômeno, houve uma ressemantização do conceito de quilombo ampliando-o e propiciando que um número crescente de comunidades passasse a se autodeterminar dessa maneira. Muitas comunidades rurais negras passaram a construir uma nova identidade, baseada no resgate do conceito de "quilombo", com o aparecimento de novos atores sociais, ampliando e renovando os modos de ver e viver a identidade negra. Neste contexto de lutas identitária, o fenômeno da memória passou a ter importância fundamental num campo de disputas por territórios, elemento essencial para a constituição da identidade do grupo.

No âmbito deste artigo não cabe discutir filigranas teóricas sobre identidade, porém é preciso esclarecer sempre que "identidade", mais do que um conceito constitui uma teoria com uma longa e polêmica história de discussão, desde que Barth, no campo da Semiologia, a sofisticou e as ciências humanas e sociais dela se apropriaram. Atualmente, alerta Pereira (2002, citado em Tosta, 2011), tal conceito "é usado abusivamente fora da vida acadêmica, como rótulo mágico e simplificador, para explicar e explorar as características da população brasileira e dos segmentos étnicos que a compõem”. Por esses e outros deslizes semânticos é:

Imprescindível fixar que a identidade é sempre uma construção histórica cultural e não um dado da biologia. Não é na cor nem nos demais traços fenotípicos de um grupo que reside sua identidade. São, antes disso, as interpretações social e cultural dadas a essas características biológicas que criam simbolicamente a identidade de um grupo (p. 425) ${ }^{7}$

Como escreveu Hall (2012, p109), “é precisamente porque as

${ }^{7}$ Sobre o debate acerca da noção histórica de identidade, vale conferir o artigo de TOSTA, 2011.

identidades são construídas dentro e não fora do discurso (de um grupo) que 
nós precisamos compreendê-las como produzidas em locais históricos e institucionais específicos, no interior de formações e práticas discursivas específicas, por estratégias e iniciativas específicas”. Tomaz Tadeu da Silva (2012, p.73-74), complementa essa ideia ao afirmar que "na perspectiva da diversidade, a diferença e a identidade tendem a ser naturalizadas, cristalizadas e essencializadas" e o "multiculturalismo" explicaria a diversidade e a diferença respaldadas por um apelo benevolente ao respeito e à tolerância. Para ele, "identidade e diferença estão numa relação de estreita dependência". Uma e outra são, pois, inseparáveis. E conclui:

Em geral, consideramos a diferença como um produto derivado da identidade. Nessa perspectiva, a identidade é referência [...] Isto reflete a tendência de tomar aquilo que somos como sendo a norma pela qual descrevemos ou avaliamos aquilo que não somos [...] na perspectiva que venho tentando desenvolver, identidade e diferença são vistas como mutuamente determinadas. (SILVA, 2012, p.76)

Pensar a diferença e a identidade como excludentes é imaginar que os quilombolas tenham resistido em suas terras até os dias de hoje, porque ficaram isolados e à margem da sociedade, cultivando práticas primitivas e originárias do tempo da escravatura. Pelo contrário, sempre se relacionaram intensa e assimetricamente com outros grupos sociais, resistindo a várias formas de violência para permanecer em seus territórios ou, ao menos, em parte deles. Mas não há como negar que essa resistência, quando se trata de cultura, não é intransponível, deixa-se influenciar por mudanças internas e externas, naturais nas relações humanas no decorrer do tempo. Também os remanescentes assistem à $\mathrm{TV}$, usam celulares e acessam a internet, como as demais pessoas, quando têm acesso a esses bens culturais por conquistarem uma situação econômica melhor.

Os estudos sobre cultura de Barros Laraia (2013, p.101) contribuem, significativamente, para a discussão que estamos desenvolvendo, pois, segundo este antropólogo, o conceito de cultura exige um pensar sobre sua dinamicidade, pelas inúmeras reformulações que vão configurando seu caráter fluido e fragmentário, comum em nosso tempo:

A cultura é dinâmica. Cada sistema cultural está sempre em mudança. Entender essa dinâmica é importante para atenuar o choque entre as gerações e evitar comportamentos 
preconceituosos. Da mesma forma que é fundamental para a humanidade a compreensão das diferenças entre povos de culturas diferentes, é necessário saber entender as diferenças que ocorrem dentro do mesmo sistema.

$\mathrm{O}$ autor evidencia que as diferenças culturais ocorrem tanto entre sistemas como dentro do próprio sistema, o que requer não apenas tolerância, mas, principalmente, compreensão e aceitação do Outro(s) em todas as possibilidades de ser e de agir no mundo, numa rede de interações que resultam em assimilação cultural recíproca. Nessa mesma linha de pensamento, Stuart Hall (2006, p.74) escreve, referindo-se à cultura nacional com relação à cultura estrangeira: "[...] é difícil conservar as identidades culturais intactas ou impedir que elas se tornem enfraquecidas através do bombardeamento e da infiltração cultural." Pensamos que a exposição a outras culturas deixam vulneráveis aqueles que se mostram acessíveis à inovação, principalmente, os mais jovens e as crianças, férteis para a aprendizagem e sempre em busca do novo.

Nas comunidades de remanescentes não é diferente, elas estão, também, susceptíveis à influências várias. Por isso mesmo, pensar a cultura afro-brasileira como se fosse africana é pensar que o tempo não passa, que as relações sociais não ocorrem em meio a permanências e mudanças e que a comunicação não existe. O processo de aculturação ocorre e resulta numa cultura plural em que influências se atravessam e se complementam. Cremos, assim, ser possível encontrar indícios das culturas africanas, principalmente a Banto, na comunidade pesquisada. Os povos afrodescendentes são sujeitos portadores de identidades que se reinventam de ancestralidade, de memória e de culturas, de religiosidade e de conhecimento. Portanto, são copartícipes na edificação da história deste país. Desse modo, é sempre bom reiterar que a igualdade de direitos não exclui, nem elimina o respeito às diferenças culturais, porque se complementam.

A História do Brasil registrou a contribuição de várias etnias na constituição do povo brasileiro. Mas, segundo Thompson (1998, p.137),

Enquanto os historiadores estudam os atores da história à distância, a caracterização que fazem de suas vidas, opiniões e ações sempre estarão sujeitas a ser descrições defeituosas, projeções da experiência e da imaginação do próprio 
historiador: uma forma erudita de ficção. A evidência oral, transformando os 'objetos' de estudo em 'sujeitos', contribui para uma história que não só é mais rica, mais viva e mais comovente, mas também mais verdadeira.

A oralidade tem revelado facetas que desconhecíamos ao trazer leituras de acontecimentos pelo viés de quem as vivenciou, ou pelas narrativas de quem as preservou contando aos seus descendentes. Nessa perspectiva, os povos tendem a ter o mesmo valor histórico e cultural, sem predominância de um sobre outros. Conforme Munanga (2010, p.50):

As heranças culturais africana e indígena constituem uma das matrizes fundamentais da chamada cultura nacional e deveriam, por esse motivo, ocupar a mesma posição das heranças europeias, árabes, judaica, orientais etc. Juntas, essas heranças constituem a memória coletiva do Brasil, uma memória plural e não mestiça ou unitária. Uma memória a ser cultivada e conservada por meio das memórias familiares e do sistema educacional, pois um povo sem memória é como um povo sem história.

Desde estas perspectivas, a importância das narrativas extraescolares efetiva-se, na medida em que os anciãos são memória viva, cujo repertório e experiência de vida compõe um rico cabedal que (trans)forma o patrimônio imaterial de sua comunidade. Nas palavras de Sodré (1999), “os valores da ancestralidade são poderosos [...] Durante todo o tempo ele é atravessado pelo discurso fundante de seu pai e sua mãe"8. A discussão sobre processos identitários, abordando aspectos conceituais e contextuais, implica, necessariamente, a concepção da identidade como uma construção social, marcada por polissemias que devem ser entendidas circunscritas ao contexto que lhe confere sentido e (re)significação. Fato é que o debate sobre identidade abrange dimensões pessoais e sociais, que surge do processo de identificação do indivíduo com aqueles que considera importantes para a sua socialização. A identidade pessoal está, assim, vinculada à identidade social, numa relação de interdependência. Desse vínculo, surge a percepção da importância da relação estudantes/escola/comunidade para a construção das identidades das crianças quilombolas, com vistas a, também, conferir significado à Lei 10.639/2003 através da voz daqueles que têm autoridade histórica para fazê-lo. Munanga (2010, p.42) escreveu: "Combinar a liberdade individual com o reconhecimento das diferenças culturais e as garantias constitucionais [...] é

${ }^{8}$ Esse conceito de pai e de mãe é tomado num sentido mais amplo e significativo que ultrapassa os laços de consanguinidade, perceptíveis na noção de ancestralidade que reconfiguram e ampliam a experiência da coletividade da circularidade do passado e do presente (re)significado pelo Sankofa. 
uma questão que leva a uma reflexão sobre a educação, pois sabemos que a lei sozinha com seu conteúdo repressivo não resolve todos os problemas".

Os quilombos, hoje, constituem um legado material e imaterial de resistência com os quais os quilombolas desenvolvem e reproduzem modos de vida característicos num determinado lugar. Conforme escreveu Paul Thompson (1998), inventar um passado imaginário, que deve ter acontecido, é uma forma de preservar suas crenças e sua ideologia, pois aquilo que o depoente acredita é, para ele, mais importante do que aquilo que realmente aconteceu. Cabe, portanto, à escola criar condições de aprendizagem em que os sujeitos compartilhem conhecimentos, valorizem os seus saberes e exercitem o respeito mútuo pela diferença.

\section{CONSIDERAÇÕES INICIAIS}

Para refletir sobre a construção das identidades de crianças quilombolas, considerando a relação escola/comunidade, é por em causa e debate os conflitos e as tensões que permeiam tal relação: de um lado, uma escola movida pela epistemologia "branca" ou normatividade da branquitude; de outro, uma cultura africano-brasileira amordaçada pela invisibilidade histórica. E nessa polissemia de vozes, levar em conta a percepção que as crianças têm sobre si mesmas. Pensamos que a escola pode facilitar a identificação dessas crianças como grupo com características físicas e culturais similares que as diferenciam das crianças de outras comunidades. Em vista disto, sua formação educacional não deve ignorar o legado dos remanescentes quilombolas para a construção de nosso país, contribuindo, assim, para que as crianças se conheçam e se reconheçam como brasileiras com direito a ter direitos numa educação que vise a construção da cidadania.

As comunidades "remanescentes de quilombos", mais que uma herança que ultrapassa o tempo, podem ser pensadas respeitando-se suas diferenças, como experiências historicamente situadas na formação social do paíse que, na luta por sua existência, desenvolveram identidades próprias. De outra forma, ajudar a pensar os problemas das populações negras como movimento de autoafirmação, valorizando a herança africana na constituição da população 
brasileira, admitindo que as heterogeneidades são importantes e necessárias e, por isso, devem ser respeitadas e valorizadas. Um dos componentes essenciais para o reconhecimento das comunidades remanescentes como parte da constituição do país, além da posse do território são os sujeitos que, nas relações interpessoais cotidianas, exercem e sofrem influência uns dos outros e de uma comunidade em relação às outras. Nesse processo, ouvir as memórias dos anciãos são recursos de pesquisa fundamentais, pois nos permite debruçar sobre o passado assim como ouvir testemunhas de outros tempos que, ao recordar o passado, impulsionam o seu entorno social a agir no presente. E, ao narrar suas experiências de vida, tornam-se bases fundadoras para a construção da identidade dos mais jovens da comunidade de remanescentes.

As questões, elencadas inicialmente, permanecem em aberto no estudo proposto. Mesmo assim, esperamos que as reflexões sugiram pesquisas e outras abordagens sobre a temática das relações entre a história e a memória, as instituições educacionais e práticas culturais, assim como suas relações entre identidade e as mudanças sociais. É por essa perspectiva teórica, que pensamos observar, enxergar e analisar a relação escola/comunidade quilombola intermediada pelas narrativas, num constante diálogo entre o presente e o passado, como parte da preparação para o devir. Encerramos a discussão? Não, ela apenas principia.

\section{REFERÊNCIAS}

BENJAMIN, Walter. Magia e técnica, arte e política: ensaios sobre literatura e história da cultura. Trad. Sérgio Paulo Rouanet. 7. ed., São Paulo: Brasiliense, 1994. (Obras escolhidas, v. 1)

BERGSON, Henri. Matéria e memória: ensaio sobre a relação do corpo com o espírito. São Paulo: Martins Fontes, 2004.

BOSI, Ecléa. Memória e Sociedade: lembranças de Velhos. São Paulo: Companhia das Letras, 1997.

BRASIL. Lei 10.639 de 9 de janeiro de 2003. Altera a Lei no 9.394, de 20 de dezembro de 1996, que estabelece as Diretrizes e Bases da Educação Nacional. Brasília: [s.n.], 2003. 
BRASIL. Lei de Diretrizes Curriculares Nacionais para a Educação das Relações Étnico-Raciais e para o Ensino de História e Cultura AfroBrasileira e Africana. Brasília: [s.n.], 2004.

BRASIL. Plano Nacional de implementação das Diretrizes Curriculares Nacionais para a Educação das Relações Étnico-Raciais e para o Ensino de História e Cultura Afro-Brasileira e Africana. Brasília: [s.n.], 2009.

CHARTIER Roger. A História ou a leitura do tempo. Belo Horizonte: Autêntica Editora, 2009.

HALL, Stuart. A identidade cultural na pós-modernidade. Tradução Tomaz Tadeu da Silva, Guaracira Lopes Louro. 11 ed. Rio de Janeiro: DP\&A, 2006.

. [2000] Quem precisa da Identidade? In. SILVA Tomaz Tadeu da (Org.) Identidade e diferença: a perspectiva dos estudos culturais. 12 ed. Petrópolis, RJ: Vozes, 2012, p.103-133.

HALBWACHS, Maurice [1925]. A memória coletiva. Tradução, Beatriz Sidou. São Paulo:

Centauro, 2006.

LARAIA, Roque de Barros. Cultura: um conceito antropológico. 16ed. Rio de Janeiro, Zahar, 2013.

MUNANGA, Kabengele. Discussões sobre o negro na contemporaneidade e suas demandas. Educação e diversidade cultural. Cadernos Penesb - EdUFF Jan/Jun./2008/2010. Revista do Programa de Educação sobre o Negro na Sociedade Brasileira Faculdade de Educação - UFF 08/2010, p. 1- 200.

NORA, Pierra. Entre história e memória: a problemática dos lugares. Revista Projeto História. São Paulo, v. 10, p. 7-28, 1993.

POLLAK, Michael. Memória, Esquecimento, Silêncio. Estudos Históricos, Rio de Janeiro, vol.2, no 3, 1989.

ROUSSO, Henry. A memória não é mais o que era. In: FERREIRA, Marieta de Moraes \& AMADO, Janaína. Usos e Abusos da História Oral. 5. Ed. Rio de Janeiro: Ed. FGV, 2002. p. 93-101.

SILVA, Tomaz Tadeu. A produção social da Identidade e da diferença In. SILVA, Tomaz Tadeu da (Org.) Identidade e diferença: a perspectiva dos estudos culturais. 12 ed. Petrópolis, RJ:Vozes, 2012. p.73-102.

SODRÉ, Muniz. Claros e escuros: identidade, povo e mídia no Brasil. Petrópolis, RJ: Vozes, 1999.

THOMPSON, Paul. A voz do passado: história oral. 2. ed Rio de Janeiro: Paz e Terra, 1998. 
TOSTA, Sandra de Fátima Pereira. Antropologia e educação- culturas e identidades na escola. Magis. Revista Internacional de Investigación em Educacion, Colômbia: Bogotá: Pontifícia Universidade Javeriana, vol.3, n. 6, p. 413-431, 2011.

TOSTA, Sandra de Fátima Pereira. SILVA, Lucas E. No meio do Caminho havia uma Escola!: História Oral e seu uso na Pesquisa Educacional. ROCHA, Gilmar. TOSTA, Sandra P.

CAETITÉ> Disponível em: < https://pt.wikipedia.org/wiki/Caetit\%C3\%A9 > Acesso em: 20.03.2015 